\title{
Cultura Cultura
}

\section{A filosofia do conhecimento em Delfim Santos}

The Philosophy of Knowledge in Delfim Santos

\section{Maria de Lourdes Sirgado Ganho}

\section{(2) OpenEdition}

\section{Journals}

\section{Edição electrónica}

URL: http://journals.openedition.org/cultura/1019

DOI: $10.4000 /$ cultura. 1019

ISSN: 2183-2021

Editora

Centro de História da Cultura

\section{Edição impressa}

Data de publição: 1 Junho 2012

Paginação: $75-81$

ISSN: 0870-4546

\section{Refêrencia eletrónica}

Maria de Lourdes Sirgado Ganho, «A filosofia do conhecimento em Delfim Santos », Cultura [Online], Vol. 29 | 2012, posto online no dia 31 outubro 2013, consultado a 30 abril 2019. URL : http:// journals.openedition.org/cultura/1019; DOI : 10.4000/cultura.1019

Este documento foi criado de forma automática no dia 30 Abril 2019.

(c) CHAM - Centro de Humanidades / Centre for the Humanities 


\title{
A filosofia do conhecimento em Delfim Santos
}

\author{
The Philosophy of Knowledge in Delfim Santos
}

Maria de Lourdes Sirgado Ganho

1 Delfim Santos é um dos pensadores portugueses que confere ao momento gnosiológico, como filosofia primeira, parte substancial da sua reflexão filosófica. Ora, esta preocupação pelo conhecimento percorre toda a sua obra, mas está já presente, de um modo muito evidente, em Situação valorativa do positivismo, de 1938, onde procura mostrar que, no âmbito de uma compreensão do que é próprio desta corrente, a filosofia emerge como algo que tende a ser ocupado pela ciência. Assim sendo, e devido à noção de progresso científico, à medida que a ciência avança a filosofia recuaria, até deixar de ser.

2 Afirma-se, pois, como hegemónico o conhecimento científico e confere-se à filosofia um carácter residual, que tenderá a ser ocupado pelo conhecimento científico. A filosofia, por enquanto, seria uma espécie de "resto".

3 Como é bem evidente, esta tese, para quem é filósofo e interroga a realidade na multiplicidade das suas manifestações, é uma tese que veicula uma concepção de conhecimento que para a atitude própria da filosofia é, claramente, redutora, porquanto deixa muitas interrogações por fazer e não dá conta do essencial da própria realidade.

4 A intenção daqueles que partilham a tese enunciada pelo "positivismo da Escola de Viena" já não é a de fundamentar na metodologia das ciências experimentais, como A. Comte o fez com a lei dos três estádios, mas antes apontar que é no processo lógico da expressão, ou na tradução dos factos experimentais (daí chamar-se-lhe empirismo lógico) que se coloca a tónica, ou seja, o que importa é a determinação do estatuto da ciência, tendo em conta a noção de verificabilidade. Ora, a filosofia não é da ordem da verificação, pelo que, para o empirismo lógico, ela não tem sentido, nem mesmo razão de ser.

5 Delfim Santos, na obra que atrás mencionámos, propõe-se mostrar a dimensão ontognosiológica que perfilha, que vai aplicar ao próprio neopositivismo, mas mostrando que esta sua reflexão vem do horizonte filosófico e não do positivista. Nesse sentido afirma: "Praticamente o que devemos aos diferentes positivismos são clarificações das 
ciências que eles já encontraram formadas, nem sempre arrumadas" ${ }^{1}$. Ora, o positivismo e o neopositivismo não têm a possibilidade de dar conta da realidade, entendida na sua totalidade.

6 Deste modo, a resposta do pensador ao que é conhecer? assim como a sua filosofia do conhecimento, enquanto reflexão sobre o ente, são pautadas por uma atitude reflexiva, interrogativa e não solucionante. A sua resposta, estribada num modo categorial, cujos autores como Aristóteles ou Nicolau Hartmann são referências iniludíveis, é dada na sua tese de doutoramento de 1940, intitulada Conhecimento e realidade, a qual, como logo nos diz, pretende introduzir a uma "teoria do conhecimento", em que a inspiração alemã e o contacto directo de alguns anos com as novas correntes filosóficas, apresentadas por $\mathrm{N}$. Hartmann e Martin Heidegger, são fundamentais².

7 Em nosso entender, e após uma análise aprofundada, esta sua obra Conhecimento e realidade mantém uma relação estreita com outra sua obra, menos nomeada, embora de grande relevância, intitulada Das regióes da realidade, onde ser e conhecer se autoimplicam. Assim sendo, talvez que a inspiração para a sua concepção de conhecimento venha mais de uma atmosfera aristotélica e hartmanniana que heideggeriana.

8 Ressalvamos, contudo, que Delfim Santos supera estas posições, pelo modo como encara o próprio problema gnosiológico, por exemplo, quando distingue na obra Da filosofia, conhecimento essencial (a que corresponde, como nos diz, o homem morto) de conhecimento existencial (ao qual corresponde a noção de homem vivo). Aquele constitui-se como objecto da ciência, este como motivo de reflexão filosófica. Coloca-se aqui, deste modo, quer a relação ciência-filosofia como diferentes modos de conhecer, como também a questão da realidade, em que esta, como nos vai dizer muito claramente na sua tese de doutoramento, tem de ser entendida relativamente ao ser real e ideal. 0 conhecimento diz respeito a esse todo (o real e o ideal, que constituem a realidade) e não apenas a parte deste.

\section{Conhecimento e realidade}

9 Entrando, deste modo, no âmago da sua posição gnosiológica, temos a interrogação central: "como é possível conhecer?" Vexata quaestio, a da possibilidade do conhecimento, que recebeu ao longo da história da filosofia diferentes aproximações, pensemos, por exemplo, na dúvida radical dos cépticos gregos, na época clássica. Com efeito, a interrogação acerca da possibilidade do conhecimento permite estabelecer a determinação e articulação entre a manifestação da realidade e a apreensão pelo sujeito dessa mesma realidade.

Será possível conhecer? Certamente que sim. E Delfim Santos evoca diferentes autores: Protágoras, Platão, Aristóteles, Berkeley, Descartes, Leibniz, Kant, para só referir os mais mencionados, sem esquecer o contributo da fenomenologia, matriz omnipresente na sua meditação.

11 Ao referir estes autores, Delfim Santos não tem a intenção de "explicar" a posição gnosiológica de cada um, dado que o que lhe interessa é, sobretudo, mostrar o contributo que cada um deles deu para a dilucidação desta questão que tem como seu horizonte a problemática da verdade. Cada autor vem com a sua linguagem, com a sua terminologia, acto que nem sempre é estimulador da reflexão, mas que é uma evidência que não pode ser esquecida. Por isso afirma: “A mutação de temas de reflexão de cada época e o esforço 
de fixação terminológica dos historiadores da filosofia são tendências inconciliáveis e originárias de confusões e pseudoproblemas"3.

Mas, então, e mais uma vez: que é conhecer? Diz-nos o autor: "uma análise aprofundada do problema mostra que a relação do conhecimento é possível, não entre idênticos, mas entre diversos" " . Tal afirmação significa que não é possível a adequação entre realidade e conhecimento, do mesmo modo que universo e homem se apresentam como irredutíveis.

Deste modo, na obra em apreço, Conhecimento e realidade, na I parte desta analisa o conhecimento e na II parte reflecte acerca da noção de realidade. E, dado que a realidade não é redutível ao conhecimento, ressalta, portanto, a necessidade de estabelecer os limites da relação conhecimento-realidade, privilegiando o conceito de verdade, na medida em que o problema do conhecimento emerge como mediador entre realidade e verdade.

\section{0 conhecimento}

Num aprofundamento acerca do que é o conhecimento, este afirma-se como relação. E um dos pólos da relação é o sujeito. Contudo, Delfim Santos afasta a possibilidade de o conhecimento poder ser, totalmente, reconduzido à subjectividade como estruturadora do princípio de identidade. O pensador, porém, distingue sujeito-empírico de sujeitotranscendental, mostrando que, quando o filósofo privilegia o sujeito empírico, como "suporte do conhecimento", acaba por colocar-se numa atitude psicológica, enquanto a consideração do sujeito transcendental permite a compreensão da filosofia como "descoberta das essências ou das ideias que permanecem no sujeito transcendental". Deste modo, se o sujeito empírico valoriza e promove o empirismo, o sujeitotranscendental valoriza o formalismo e o logicismo.

Ora, este dualismo, presente ao longo da história da filosofia, quanto à função do sujeito no processo cognitivo é já um "avançar" no caminho da "solução", dado que o erro fundamental foi superado, isto é, Delfim Santos não admite uma perspectiva monista, no que diz respeito à consideração do sujeito ou do objecto como fundamentais na constituição do conhecimento. E Delfim Santos interroga-se: “ terá a escolha de ser exclusiva?" E se não, poderão estas duas tendências ser complementares ${ }^{5}$ ?

Segundo o filósofo em apreço, só com Kant foi quebrada esta "monotonia pendular", que mostra que a tese medieval do conhecimento como adaequatio rei não é possível. Há, então, que reter esta instância crítica, ainda que Delfim Santos se não vá deter nela, pois decididamente reconhece o grande contributo de Kant para o conhecimento, já que valoriza sujeito e objecto no acto de conhecimento.

17 Mas, se o pensador não aceita a tese da adaequatio rei, de qualquer modo está preocupado com uma progressiva adequação dos princípios do conhecimento aos princípios do ser (e aqui, reconhece todo o sentido e valor da tese kantiana, mas sem dúvida, supera Kant), ainda que se não possua um critério para averiguar em que medida a estrutura cognoscitiva corresponde à instância ontológica. Ora, esta progressiva adequação dos princípios do conhecer aos princípios do ser implica, na linha fenomenológica, a valorização do "descrever" e a desvalorização do "explicar".

18 Para o autor, a descrição é fundamental no conhecimento - conhecer não é explicar - e por isso nos diz: "Explicar tem em si, visivelmente, o sentido de exteriorização, de 
movimento de dentro para fora. Conhecer, intuir, ver, pelo contrário, o sentido de fora para dentro"'.

19 O conhecer é, portanto, um "ver", sendo a "discriminação" o momento preparatório para esta "visão", que deve ser tão precisa, quanto possível, do fenómeno em si mesmo. A "discriminação" é, pois, a instância crítica, segundo Platão, e que prepara para a visão do fenómeno, em si mesmo, ou seja, "tal qual é".

20 Assim, e de um modo sintético, podemos afirmar que o conhecer corresponde à procura da determinação, tão rigorosa quanto possível, do fenómeno, de tal modo que se está perante uma investigação do que as coisas são "enquanto assim são" 7 , mas tendo em consideração a dificuldade de acordo entre a possibilidade de apreensão do sujeito e a manifestação da realidade. $\mathrm{E}$ como síntese desta dificuldade própria da reflexão filosófica, temos o § 20 - "Descrição Fenomenológica".

21 Aqui, Delfim Santos considera que o conhecimento realiza "o sentido da adequação entre o ideal e o real" de tal modo que o conhecimento é sempre relação entre diferentes, sendo tarefa do filósofo e da filosofia procurar os pontos de contacto, os acordos entre esses pólos diferentes - permanecendo como nostalgia de unidade a possibilidade de uma identidade entre os dois termos de relação.

\section{A realidade}

A realidade é o que aparece e este aparecer é uma representação e, como nos diz o autor, tem a ver com "o problema da substância e dos universais, da existência dos géneros e dos indivíduos, são problemas em íntima conexão com o problema da determinação da realidade e dos seus modos de manifestação"

Nesse sentido, o problema da realidade tem de ser compreendido em articulação com a temática das "regiões da realidade". Tanto esta obra que estamos a interpretar como a obra Das Regiões da Realidade, que trataremos mais à frente, colocam a questão das categorias do conhecimento. A cada região da realidade corresponde uma categoria do conhecimento.

As categorias têm a função de estabelecer uma relação, pois não são, como nos diz o autor, reproduções "adequadas" das propriedades dos objectos, e tal facto significa que não existe uma coincidência entre o sujeito, na sua função cognoscitiva, e a realidade, o que se dá é uma coordenação de determinados elementos do ser fenoménico com o ser em si das coisas, e essa coordenação garante a objectividade do próprio conhecimento.

o "pensamento é intencionalidade" para Delfim Santos e, portanto, pressupõe algo e, nesse sentido, ele é um acto de transcendência para o mundo real e ideal. Por isso, afirma o filósofo: "o momento essencial do conhecimento é a 'transcensão"'?. Podemos verificar que é clara a influência de N. Hartmann, assegurando uma concepção objectivista das categorias. De facto, as categorias têm uma função mediadora e determinam, por um lado, o que é comum a todos os níveis da realidade, por outro o que é próprio de cada um. Ora, esta questão está bem patente na obra Das Regiões da Realidade.

O que aqui nos interessa, neste momento, é perceber que a "equação entre ratio essendi e ratio cognoscendi", que o filósofo afirma, permite que as categorias assegurem uma correspondência fundamental, de tal modo que, conforme refere: "Entre a unidade da razão e a pluralidade do real manifesta-se uma relação de ordem mutual" ${ }^{10}$, e por isso 
mesmo, Delfim Santos expressa-se do seguinte modo: "a conviç̧ão de que a determinação das categorias do conhecimento e da realidade é o trabalho preliminar para o bom resultado do labor filosófico" ${ }^{11}$, mas tendo em consideração que há uma diferença entre os princípios do ser e do conhecer. Aproximamo-nos, assim, da obra Das Regiões da Realidade, que é chave para compreender o horizonte transobjectivo do conhecimento e a sua "ontofenomenologia", nas palavras de José Marinho ${ }^{12}$. Para um maior esclarecimento desta "ontofenomenologia", temos a tematização que Luís Manuel A. V. Bernardo apresenta a propósito da articulação entre realidade e conhecimento, mencionando: “/.../ não é o ser do conhecimento que esgota a fenomenologia, mas a fenomenologia que confirma a intuição do ser do conhecimento, expressa axiomaticamente, como conhecimento do ser"13.

\section{As regiões da realidade}

O que está em causa na obra Das Regiões da Realidade, de pendor claramente ontológicometafísico, no que diz respeito ao conhecimento, é a necessária compreensão da relação conhecimento - regiões da realidade, e isto porque a cada região da realidade corresponde um princípio de conhecimento, pelo que o conhecimento é sempre categorial e a cada região corresponde uma ou mais categorias. Assim sendo, podemos afirmar que a sua gnosiologia tem um horizonte ontológico-metafísico, porque, ao tematizar a articulação entre conhecimento e realidade, inscreve no processo de conhecer o horizonte mais vasto e englobante desse horizonte fundamentador.

O conhecimento, porém, possui um alcance mais limitado, pois ele é tão-só uma das manifestações da realidade, pelo que há sempre algo para lá do cognoscível. Verdadeiramente, só se conhece o que se constitui como objecto, e a realidade, como já vimos, na linha do pensamento de N. Hartmann, é transobjectiva.

Ora, a obra que estamos a interpretar mostra bem este aspecto, pois apresenta como que uma fundamentação de que o conceito de realidade não é redutível ao plano gnosiológico e, nesse sentido, afirma uma determinação mais vasta da própria realidade a partir de outros aspectos, tais como o axiológico, o ontológico e o metafísico.

As categorias descrevem e explicam as regiões - há categorias que explicam uma região, mas que não podem explicar a seguinte. Ora, isto significa que, a par de uma gnosiologia categorial, não monista, há uma ontologia regional que aceita que a cada região da realidade correspondem certas categorias que não podem ser transpostas. Por exemplo, quando Delfim Santos refere as quatro regiões da realidade: matéria, vida, consciência e espírito, faz corresponder a cada uma delas uma categoria: causalidade, finalidade, intencionalidade e liberdade.

31 Aplicar à região da matéria a categoria da liberdade é impossível, embora a matéria seja a base para a vida, a consciência e o espírito. Do mesmo modo, explicar a liberdade a partir da matéria é explicar o superior a partir do inferior, portanto, estar-se-ia perante uma transposição indevida.

32 A compreensão tem de ser ascendente e hierarquizada - coloca-se aqui a questão ontológico-metafísica, e se temos a possibilidade de conhecer cada uma destas regiões é mediante categorias que se adequam à região em questão. Com categorias inferiores não podemos conhecer aquilo que é superior. 
33 A análise categorial é, sem dúvida, a superação de qualquer visão monista da realidade. Como nos diz na obra em apreço, é necessário estabelecer "as categorias adequadas ao conhecimento de cada uma das regiões"14. Só assim se afirma, de verdade, uma ontofenomenologia, que nos permite compreender a relação entre conhecer e ser.

\section{Conclusão}

Para concluir brevemente, podemos afirmar que muitos outros aspectos ficaram por tratar, como por exemplo, a relação entre conhecimento científico e conhecimento filosófico, em que a propósito deste último se coloca a questão existencial. A verdade é que a riqueza do pensamento de Delfim Santos não permite uma conclusão neste breve espaço, pois o seu pensamento constitui-se sempre como um desafio hermenêutico, portanto como pensamento interrogativo e que se oferece a um aprofundar constante.

\section{NOTAS}

1. Santos, Delfim, Obras Completas, Lisboa, Fundação Calouste Gulbenkian, 1971, 1. ㄹ. ed., vol. I, p. 173 (sigla O.C. I, II, III, IV, conforme o n.. do volume).

2. O. C., I, p. 277.

3. O. C., I, p. 279.

4. O. C., I, p. 306.

5. O.C., I, p. 302.

6. O. C., I, p. 289.

7. O. C., I, p. 291.

8. O. C., I, p. 294.

9. O. C., I, p. 315.

10. O. C., I, p. 321.

11. O. C., I, p. 322.

12. Cf. Marinho, José, “A ontofenomenologia em Delfim Santos”, in Estudos sobre o Pensamento Português Contemporâneo, Lisboa, Biblioteca Nacional, 1981.

13. Bernardo, Luís Manuel A. V., "Conhecimento e realidade em Delfim Santos", in "Delfim Santose a Escola do Porto - Actas do Congresso Internacional, org. Cristiana Soveral, Lisboa, INCM, p. 292.

14. O. C., I, p. 272.

\section{RESUMOS}

A intenção deste artigo é pôr em evidência a problemática do conhecimento em Delfim Santos, articulando conhecimento, realidade e verdade. Procura-se mostrar que há no pensamento deste 
autor uma reflexão gnosiológica que implica a consideração de "regiões da realidade", que possuem, simultaneamente um alcance gnosiológico e ontológico.

The main purpose of this paper is to stress the way Delfim Santos dealt with the problem of knowledge in establishing a connection between knowledge, reality and truth. Consequently, it intends to show that there's a concern with knowledge in the author philosophical thought, that implies the idea of "regions of reality" bearing, at the same time, a cognitive and an ontological scope.

\section{ÍNDICE}

Keywords: Delfim Santos, philosophy of knowledge, reality, regions of reality, ontology Palavras-chave: Delfim Santos, filosofia do conhecimento, realidade, regiões da realidade, ontologia

\section{AUTOR}

\section{MARIA DE LOURDES SIRGADO GANHO}

CEFI - Faculdade de Ciências Humanas da Universidade Católica Portuguesa

Doutora em Filosofia, pela Universidade Católica Portuguesa desde 1996, com a tese Consciência e Intersubjectividade em Jean Nabert, publicada na Série Universitária da Imprensa Nacional-Casa da Moeda, 2002; e Mestre em Filosofia Contemporânea, tendo apresentado a tese Existência e Transcendência em Gabriel Marcel, publicada pela Revista Itinerarium, Braga, 1994. Docente da Universidade Católica Portuguesa, desde 1983, tem leccionado Filosofia em Portugal, Antropologia Filosófica, Filosofia do Conhecimento, Filosofia Moderna, Filosofia Contemporânea. Tem também leccionado nos Mestrados de Filosofia, nomeadamente, no Mestrado de Filosofia da Linguagem e Ciências Cognitivas. É sócia do “Centro Studi Antoniani” de Pádua, desde 1982; membro da "Sociedade Científica da Universidade Católica Portuguesa"; sócia do "Instituto de Filosofia Luso-Brasileira"; membro do CEFi da UCP. Conferencista, tem cerca de oitenta títulos publicados, com referência ao livro Existir e Ser. Textos de filosofia, poesia e espiritualidade, Lisboa, IN-CM, 2009.

PhD from the Catholic University of Portugal (1996) with the thesis Consciência e intersubjectividade em Jean Nabert, which was published by the Imprensa Nacional - Casa da Moeda in 2002. Master in philosophy with the thesis Existência e transcendência em Gabriel Marcel, published in the Journal Itinerarium, Braga in 1994. Professor of philosophy at the Catholic University of Portugal since 1983 where she has taught Portuguese Philosophy, Philosophical Anthropology, Philosophy of Knowledge, Modern and Contemporary Philosophy, both in license and master degrees. Member of the "Centro Studi Antoniani" of Padova, since 1982, member of the "Instituto de Filosofia Luso-Brasileira", member of the CEFI (philosophy center of research) at Catholic University. Lecturer, she has published around 80 published titles, among which the recent book Existir e ser. Textos de filosofia, poesia e espiritualidade. Lisboa, INCM, 2009 